\title{
Effect of pH Values on the Formation of Magnesia Doped Zirconia by Ball-Mill Assisted Co-precipitation Method
}

\author{
Sukhbayar Gankhuyag and Dong Sik Bae \\ Department of Convergence Materials Science and Engineering, Changwon National University, Gyeongsangnam-Do 641-773, \\ Republic of Korea
}

\begin{abstract}
We have studied the effect of magnesia (MgO) addition $(0,5,10$, and $20 \mathrm{~mol} \%)$ in zirconia at $\mathrm{pH}$ values $(7,9,11)$. The magnesia doped zirconia $\left(\mathrm{MgO}-\mathrm{ZrO}_{2}\right)$ has been synthesized by a co-precipitation method using ammonium hydroxide as a mineralizer. As-prepared samples were characterized by XRD, FE-SEM, and TG-DSC. The XRD results showed that the quantity of tetragonal phase was increased with increasing $\mathrm{pH}$ value during synthesis. On the other hand, a decrease in the crystallite size of tetragonal phase was observed with increasing $\mathrm{pH}$ value. Therefore, the FE-SEM micrograph showed a clear decline in the particle size with increasing $\mathrm{pH}$ value. As-precipitated at $\mathrm{pH} \sim 11$, the addition of $10 \mathrm{~mol} \%$ of $\mathrm{MgO}$ showed nearly pure tetragonal phase with a crystallite size of $\sim 34.16 \mathrm{~nm}$.
\end{abstract}

Key words: Zirconia, phase-stabilization, magnesia, co-precipitation, sintering.

\section{Introduction}

Zirconia $\left(\mathrm{ZrO}_{2}\right)$ has attracted much attention due to their fascinating chemical inertness and mechanical properties. Based on these properties, $\mathrm{ZrO}_{2}$ mainly used in biomaterials, refractories, catalysis, high strength tools, SOFC (solid oxide fuel cell) and thermal barrier coatings [1-7]. The $\mathrm{ZrO}_{2}$ existed in three well-known structural forms: monoclinic, tetragonal, and cubic phase, which is known as the polymorphic form of the $\mathrm{ZrO}_{2}$. The monoclinic phase exists up to a temperature of $1,170{ }^{\circ} \mathrm{C}$, the tetragonal phase from 1,170 to $2,370{ }^{\circ} \mathrm{C}$, and the cubic phase from 2,370 to $2,680{ }^{\circ} \mathrm{C}$. The melting point of $\mathrm{ZrO}_{2}$ is 2,680 ${ }^{\circ} \mathrm{C}$ [8]. The most applicable phase of $\mathrm{ZrO}_{2}$ is tetragonal and cubic phase because of the stability at high temperature.

The properties of $\mathrm{ZrO}_{2}$-based materials substantially depend on the type of structural phases. For instance, tetragonal stabilized $\mathrm{ZrO}_{2}$ used to fabricate high strengthen tools or tough materials, whereas refractory materials needed cubic $\mathrm{ZrO}_{2}$.

Corresponding author: Dong Sik Bae, professor, research field: nano materials fabrication and processing.
Hence, the most encountering objective is the stabilization of tetragonal or cubic phase of $\mathrm{ZrO}_{2}$. The most efficient method to make tetragonal or cubic phase stabilized $\mathrm{ZrO}_{2}$ is using low valence oxides as a dopant material. These dopant including $\mathrm{CaO}$ [9], $\mathrm{MgO}$ [10], $\mathrm{Y}_{2} \mathrm{O}_{3}$ [11], $\mathrm{CeO}_{2}$ [12], $\mathrm{Al}_{2} \mathrm{O}_{3}$ [13] were used to achieve fully or partially stabilized $\mathrm{ZrO}_{2}$. Therefore, the properties of the doped $\mathrm{ZrO}_{2}$ material strongly depend on particle size and surface area which is closely related to the fabrication methods [14].

Besides, synthesis methods are essential to get stabilized $\mathrm{ZrO}_{2}$ where co-precipitation [15-17], hydrothermal [18-20], sol-gel processing [21-23], and ball-milling are most useful techniques. The co-precipitation method is simplest and costs effective way to obtain partially or fully stabilized $\mathrm{ZrO}_{2}$. However, the main difficulties in co-precipitation method are controlling the $\mathrm{pH}$ value to the phase stabilization of $\mathrm{ZrO}_{2}$. Davis et al. [24] reported that the tetragonal phase could be made at low (3-5) and high range (13-14) of $\mathrm{pH}$ values using pure $\mathrm{ZrO}_{2}$ by using co-precipitation method. However, they 
obtained monoclinic phase in the medium $\mathrm{pH}$ (8-11) range. Thus, there is a big challenge to get tetragonal or cubic phase stabilized $\mathrm{ZrO}_{2}$ in the medium $\mathrm{pH}$ levels.

This work is aimed to evaluate the effect of $\mathrm{pH}$ level in the basic region of the polymorph transportation in $\mathrm{ZrO}_{2}$. In this report, four different concentrations of $\mathrm{MgO}$ are utilized to stabilize zirconia. The $\mathrm{pH}$ values were controlled by $\mathrm{NH}_{4} \mathrm{OH}$ as mineralizer at 7, 9 and 11. In summary, the phase transformation and microstructure changes are characterized using XRD, FESEM instruments.

\section{Materials and Methods}

\subsection{Materials}

Zirconium oxychloride $\left(\mathrm{ZrOCl}_{2} \cdot 8 \mathrm{H}_{2} \mathrm{O}, 99.0 \%\right)$ and Magnesium nitrate $\left(\mathrm{Mg}\left(\mathrm{NO}_{3}\right)_{2} \cdot \mathrm{H}_{2} \mathrm{O}, 99.9 \%\right)$ were used as a precursor of initial solution without further purification. Ammonium hydroxide $\left(\mathrm{NH}_{4} \mathrm{OH}, 25-28 \%\right)$ was also used to obtain a precipitate as a mineralizer and distilled water used as a solvent.

\subsection{Methods}

The typical experimental procedure that is used to obtain $\mathrm{MgO}$-doped $\mathrm{ZrO}_{2}$ composite material was schematically illustrated in Scheme 1. Briefly, four different concentrations of $\mathrm{ZrO}_{2}$ and magnesium precursors individually were dissolved in distilled water, and total solution concentration kept at 0.3 moles. Then, the $\mathrm{pH}$ value was adjusted at 7, 9, and 11 using $\mathrm{NH}_{4} \mathrm{OH}$. The precipitated solution was ball-milled at milling speed of $160 \mathrm{rpm}$ for $6 \mathrm{~h}$. Hereupon, the precipitated solution was dried in an oven at $100{ }^{\circ} \mathrm{C}$ for four days and calcined at $800{ }^{\circ} \mathrm{C}$ for $2 \mathrm{~h}$.

TG-DSC analysis was carried out to investigate weight losses and thermal decomposition of powders. As-precipitated at $\mathrm{pH}$ value 11 samples were placed in a platinum crucible and heated up to $1,200{ }^{\circ} \mathrm{C}$ in atmospheric condition with the rate of $20{ }^{\circ} \mathrm{C} / \mathrm{min}$ using a STA N-1500 SCINCO equipment. The calcined

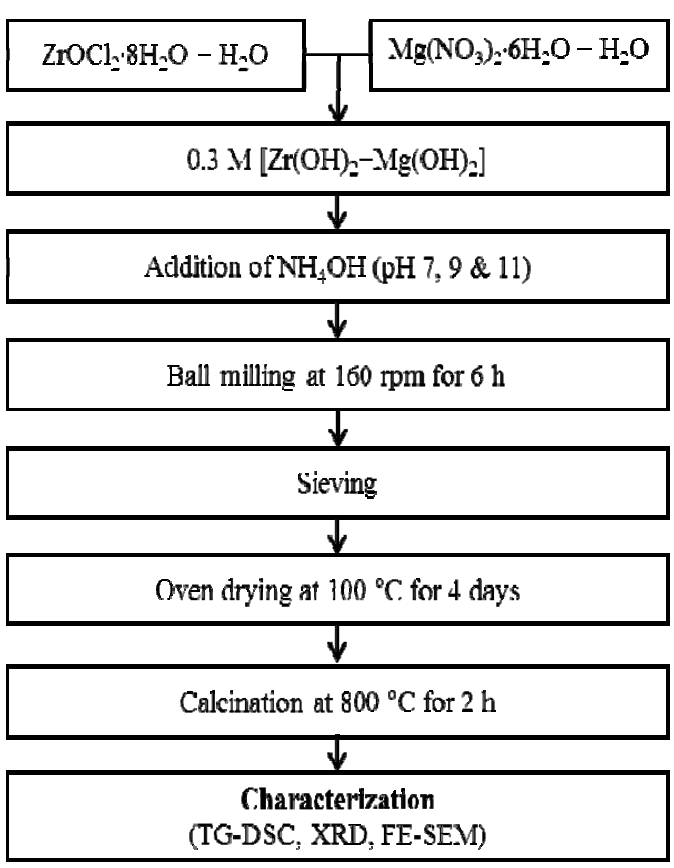

Scheme 1. Experimental procedure.

powders were examined by FE-SEM using CZ/MIRA I LMH operated at $20 \mathrm{kV}$.

Furthermore, X-ray diffraction technique was used to explore the structure of obtained material. The phase quantification analysis was performed by using Eq. (1), and the average crystallite size was estimated using Scherrer's Eq. (2).

$$
\begin{gathered}
W_{t}=\frac{I_{(h k l) t}}{\left(I_{(h k l) m}+I_{(h k l) t}+I_{(h k l) m}\right)} \\
D=\frac{0.9 \lambda}{\beta \cos \theta}
\end{gathered}
$$

\section{Results and Discussion}

\subsection{Powder Analysis}

The weight loss and thermal decomposition was clearly shown as-precipitated at $\mathrm{pH}$ value 11 (Figs. 1a and 1b). Weight loss of samples which became constant from $800{ }^{\circ} \mathrm{C}$ and the DSC curve shows endothermic and exothermic peaks (Fig. 1a). The endothermic peaks indicated elimination of adsorbed water and hydroxide form at a temperature of 110, 198, and $210{ }^{\circ} \mathrm{C}$. The zirconium hydroxide $\left(\mathrm{ZrO}(\mathrm{OH})_{2}\right)$ to $\mathrm{ZrO}_{2}$ decomposition that was revealed in the endothermic peaks at the range of $230-340{ }^{\circ} \mathrm{C}$. These 

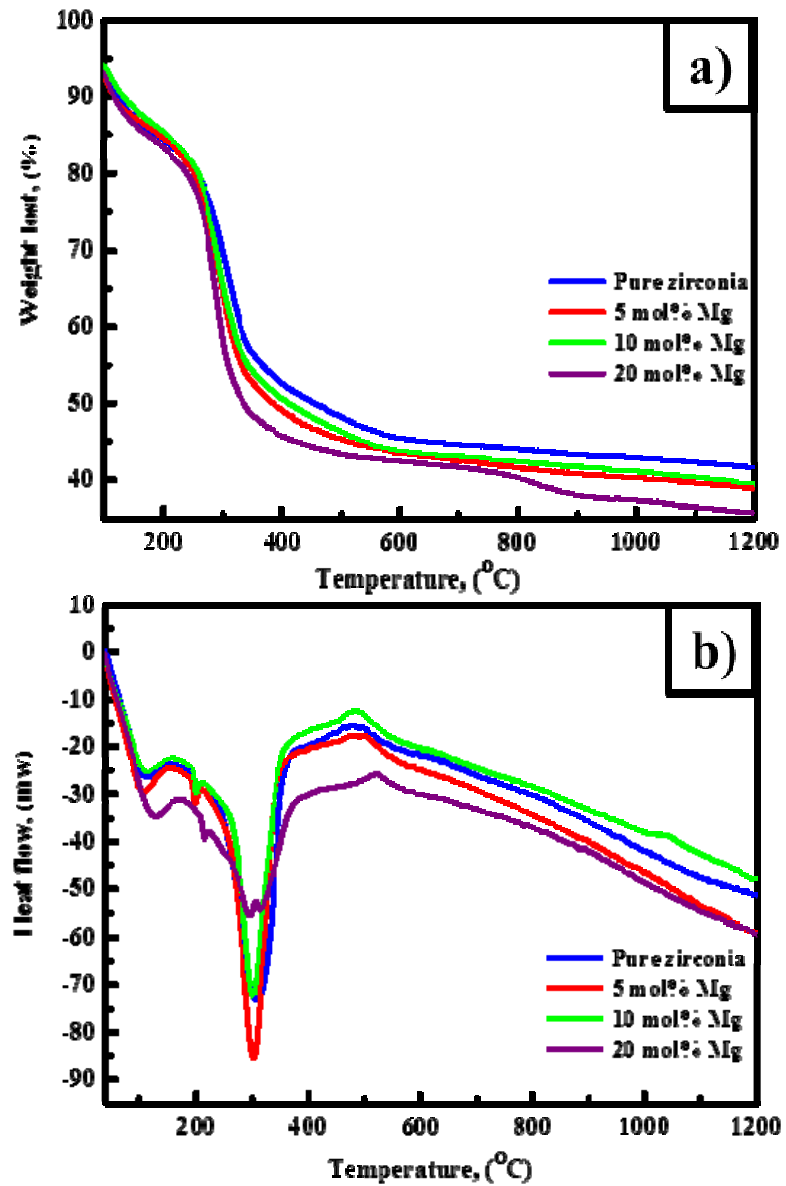

Fig. 1 The thermal decomposition analysis of precursor precipitated at pH 11 (a) TG, and (b) DSC.

peaks intensity were slightly distinguished due to the addition of dopant concentration.

The exothermic peak is related to fast crystallization into metastable tetragonal zirconia; it was shown at temperature region of $487.5-514{ }^{\circ} \mathrm{C}$ (Fig. 1b). Phase transformation temperature was changed [25], which might be due to the addition of dopant concentration or difference in particle size. Furthermore, it can be possible to cause that in the specific surface area, surface free energy is larger when the particle size of the powder is smaller, which results in a lower transformation temperature that could be formed [26].

\subsection{Phase Characterization}

Four different concentrations of $\mathrm{MgO}$ doped $\mathrm{ZrO}_{2}$ samples were prepared by controlling the $\mathrm{pH}$ values as
7, 9, and 11. XRD analysis was used to analyze the impact of $\mathrm{pH}$ values on the phase changes of $\mathrm{ZrO}_{2}$, with $\mathrm{MgO}$ content of $0,5,10$, and $20 \mathrm{~mol} \%$, respectively (Fig. 2). As for crystal phase determinations, the scans were selected from 10 to $80^{\circ}$ in the $2 \theta$ region. The pattern exhibits peaks at the $2 \theta$ region of $30.2,34.7,35.3,50.38,59.48,60.3,63.1$, and $74.78^{\circ}$ corresponding to the tetragonal phases of $\mathrm{ZrO}_{2}$ in all XRD patterns.

The as-precipitated at $\mathrm{pH}$ value 7 , the fraction of tetragonal phase was increased with increasing $\mathrm{MgO}$ dopant concentration (Fig. 2a). Therefore, monoclinic phases are clearly shown at 24.02, 28.26, 31.36, 38.76, $41.04,45.18,54.04$, and $55.52^{\circ}$ of the $2 \theta$ region in the XRD pattern, with small peaks. The fraction of monoclinic phase was high at the pure $\mathrm{ZrO}_{2}$ with the percentage of $67.1 \%$ (Fig. 2a). The addition of $\mathrm{MgO}$ affected up to $10 \mathrm{~mol} \%$ of dopant to get nearly pure tetragonal phase. However, at the $20 \mathrm{~mol} \%$ of $\mathrm{MgO}$, the fraction of monoclinic phase was slightly increased. Perhaps, it is also possible to cause the excess amount of $\mathrm{MgO}$ or some contaminants as nitrate ion or chlorine from starting material. These findings suggest that the $10 \mathrm{~mol} \%$ of $\mathrm{MgO}$ might be the proper way to obtain purely tetragonal phase as-precipitated at $\mathrm{pH}$ value 7 .

The samples are precipitated at $\mathrm{pH}$ value 9 which shows increased tetragonal phase, with all samples but slightly for $\mathrm{MgO}$ dopant compared to $\mathrm{pH}$ value 7 (Fig. 2b). Besides, the monoclinic peak was revealed in the $2 \theta$ region of 24.02 on all samples. This may have been caused by the excess amount of ammonium hydroxide. As for $\mathrm{MgO}$-doped $\mathrm{ZrO}_{2}$, their fraction of tetragonal was tended to increase compared to that was precipitated at $\mathrm{pH}$ value 7 .

Remarkably, most of the $\mathrm{ZrO}_{2}$ materials were purely tetragonal as-precipitated at $\mathrm{pH}$ value 11 . Although the pure $\mathrm{ZrO}_{2}$ precipitated at $\mathrm{pH}$ value 11, produces a material with $10.71 \%$ or less of the tetragonal phase. Moreover, the $10 \mathrm{~mol} \%$ of $\mathrm{MgO}$ showed extremely pure tetragonal phase without any 

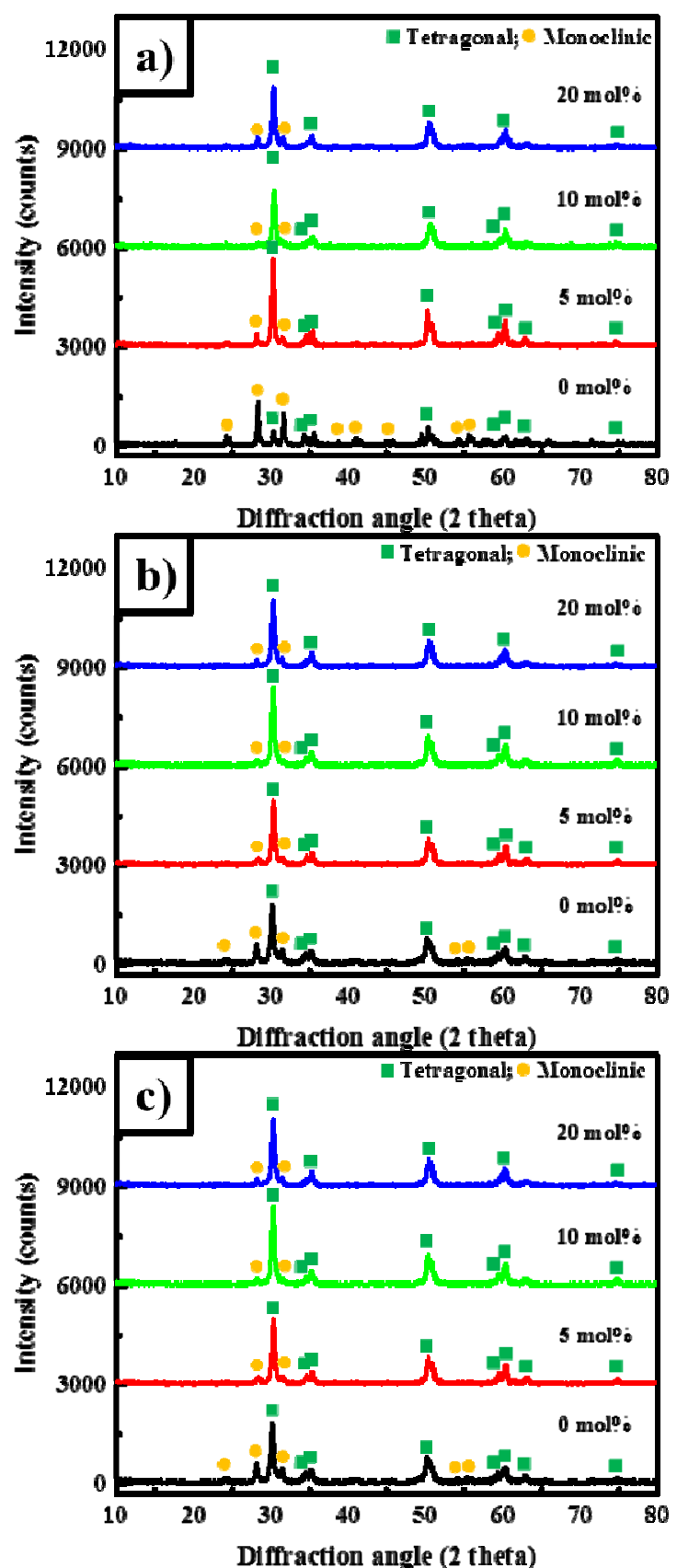

Fig. 2 The XRD pattern of samples calcined at $800{ }^{\circ} \mathrm{C}$ for 2 hours (a) pH 7, (b) pH 9, (c) pH 11.

monoclinic peaks, as depicted in Fig. 2c. These results provide further support for the hypothesis that is increasing the $\mathrm{pH}$ values affected to get the pure tetragonal phase of $\mathrm{ZrO}_{2}$ with the addition of magnesia. Particularly, the pure tetragonal phase was obtained as-precipitated at $\mathrm{pH}$ value 11 , with the addition of $10 \mathrm{~mol} \%$ magnesia. As reported by Davis et al. that the monoclinic phases are formed in the medium $\mathrm{pH}$ region (8-11). However, in this study, the purely tetragonal phases are obtained in the medium $\mathrm{pH}$ region (7-11). Probably, this is due to the effect of dopant concentration and ball-milling.

The effect of the $\mathrm{pH}$ value on the crystallite size and phase quantity was plotted and (Fig. 3). The crystallite size was calculated from the peak width at the half maximum intensity of the total quantity of tetragonal peaks. As for each prepared sample, the $\mathrm{pH}$ values affected and crystallite size decreased from 61.5 to $31.6 \mathrm{~nm}$, with increasing $\mathrm{pH}$ values. When the fraction of tetragonal phase was less the crystallite size was bigger. The material derived from precipitation in either the 7 or 11 shows similar crystallite sizes approximately $33-34 \mathrm{~nm}$, with the addition of 10 and $20 \mathrm{~mol} \%$ magnesia. As for $10 \mathrm{~mol} \%$ of magnesia, the crystallite size was slightly bigger than $20 \mathrm{~mol} \% \mathrm{MgO}$
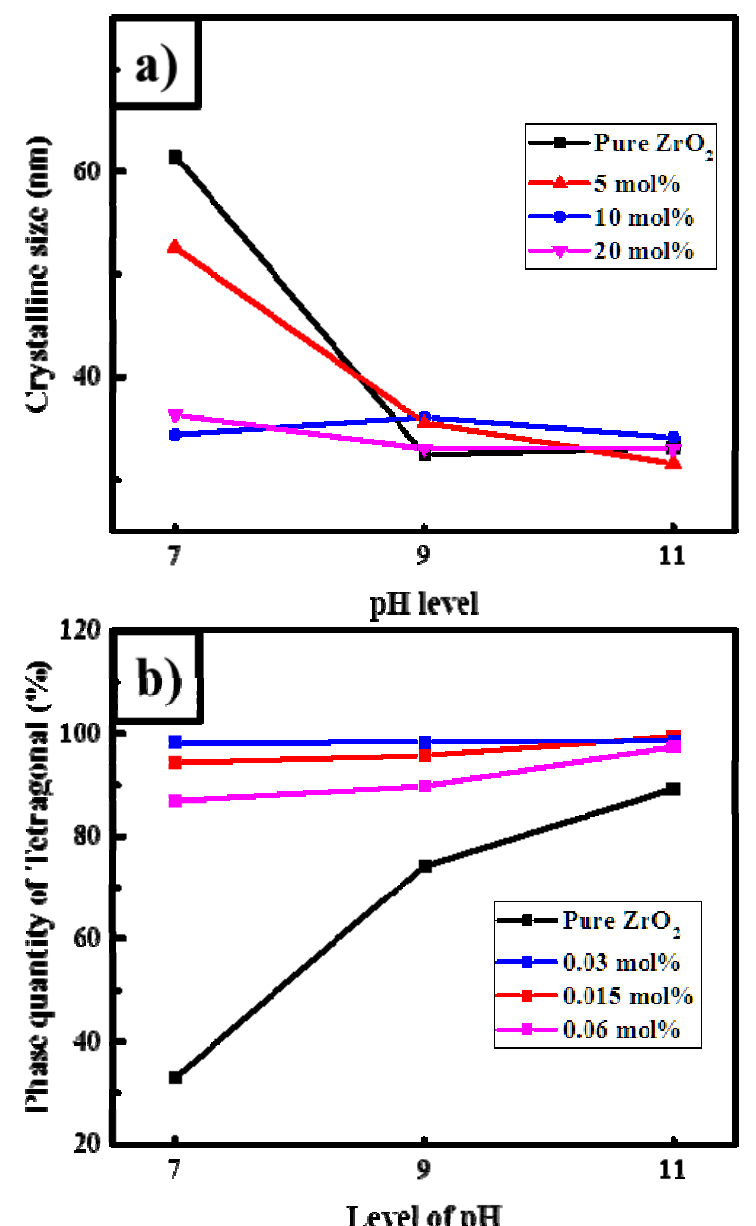

Fig. 3 Effect of the pH values on the (a) crystallite size and (b) phase transformation of $\mathrm{Mg}-\mathrm{ZrO}_{2}$ samples. 

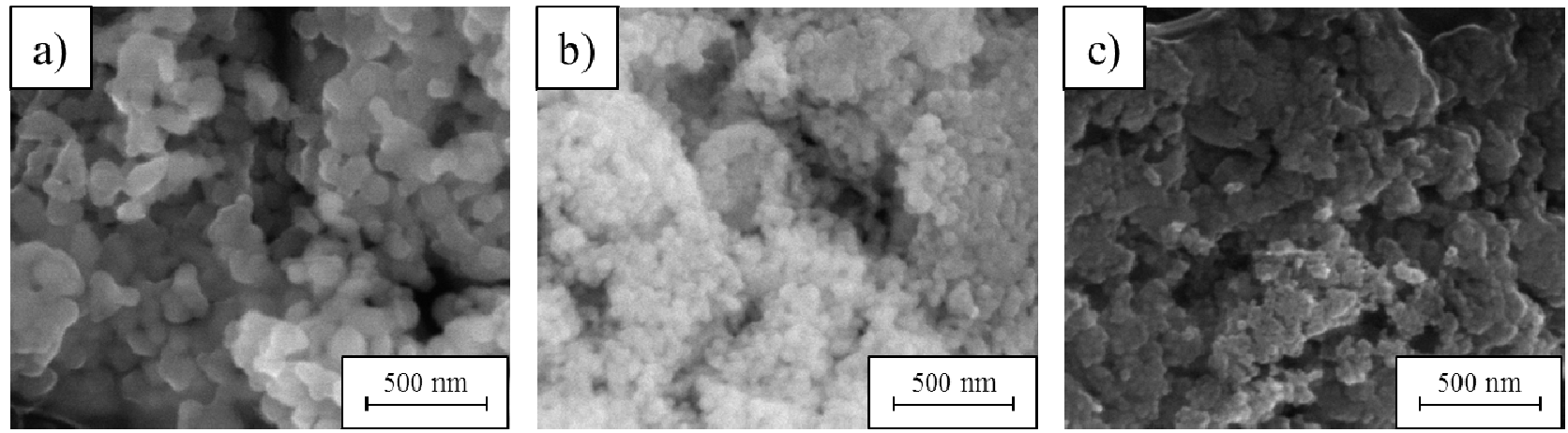

Fig. 4 The morphology of the pure zirconia sample calcined at 800 for 2 h, (a) pH 7, (b) pH 9, (c) pH 11.

while precipitated at $\mathrm{pH}$ value 9 (Fig. 3a).

\subsection{Morphology}

Fig. 4 shows the FESEM micrographs of pure $\mathrm{ZrO}_{2}$ particles prepared at different $\mathrm{pH}$ values as 7,9 , and 11. The average particle size was decreased with increasing $\mathrm{pH}$ values and agglomeration takes place as indicated in Figs. 4a-4c. The micrographs showed spherical and agglomerated particles. The powders precipitated at $\mathrm{pH} 7$; the average particles size was approximately $80 \mathrm{~nm}$ sized. However, as precipitated at $\mathrm{pH}$ values 9 and 11, the average particle size was substantially decreased approximately $40 \mathrm{~nm}$ and less than $20 \mathrm{~nm}$ sized, as indicated in Figs. 4b and 4c.

\section{Conclusion}

In summary, $\mathrm{MgO}$-stabilized $\mathrm{ZrO}_{2}$ was prepared by ball-mill assisted co-precipitation method. The $\mathrm{pH}$ values are being effected on the tetragonal stabilized zirconia. The fraction of tetragonal phase was increased with increasing $\mathrm{pH}$ value and also increasing dopant concentration.

Particularly, the relatively pure tetragonal phase was formed as-precipitated at $\mathrm{pH}$ value 11 , with the addition of $10 \mathrm{~mol} \%$ of magnesia. As for pure zirconia, the fraction of tetragonal phase was substantially increased with increasing $\mathrm{pH}$ value. It is the most appropriate result to show the effect of $\mathrm{pH}$ values on the phase transformation. On the other hand, the crystallite size tended to decrease with increasing $\mathrm{pH}$ values as for pure zirconia and $5 \mathrm{~mol} \%$ of magnesia.
Besides, the crystallite size became stable, with the addition of 10 and $20 \mathrm{~mol} \%$ magnesia.

\section{Acknowledgments}

This work was supported by the Human Resourse Training Program for Regional Innovation and Creativity through the ministry of Education and National Research Foundation of Korea (2015H1C1A1035600).

\section{References}

[1] Lyon, D., Chevalier, J., Gremillard, L., and Cam, C. D. 2011. "Zirconia as a Biomaterial." Compr. Biomater. 20: 95-108.

[2] Jamali, H., Mozafarinia, R., Shoja Razavi, R., and Ahmadi-Pidani, R. 2012. "Comparison of Thermal Shock Resistances of Plasma-Sprayed Nanostructured and Conventional Yttria Stabilized Zirconia Thermal Barrier Coatings." Ceram. Int. 38: 6705-12.

[3] Furuta, S., Matsuhashi, H., and Arata, K. 2006. "Biodiesel Fuel Production with Solid Amorphous-Zirconia Catalysis in Fixed Bed Reactor." Biomass and Bioenergy 30: 870-3.

[4] Peck, D. H. et al. 2007. "Fabrication of Porous Structure with Scandia Stabilized Zirconia Electrolyte for Solid Oxide Fuel Cells." In ECS Transactions 7: 2187-95.

[5] Mandal, N., Doloi, B., and Mondal, B. 2011. "Development of Flank Wear Prediction Model of Zirconia Toughened Alumina (ZTA) Cutting Tool Using Response Surface Methodology." Int. J. Refract. Met. Hard Mater. 29: 273-80.

[6] Zhao, X. et al. 2014. "Structural and Optical Properties of Zirconia Thin Films Deposited by Reactive High-Power Impulse Magnetron Sputtering." Thin Solid Films 570: 404-11.

[7] Lee, J. H. et al. 2001. "Electrical Conductivity and Defect 
Structure of Yttria-Doped Ceria-Stabilized Zirconia." Solid State Ionics 144: 175-84.

[8] Huang, R. T. et al. 2014. "Characterization of the Irradiation-Induced Phase Transition in the Monoclinic Polymorph of Zirconia." Nucl. Instruments Methods Phys. Res. Sect. B Beam Interact. with Mater. Atoms 332: 293-7.

[9] Broda, M., and Müller, C. R. 2014. "Sol-Gel-Derived, CaO-Based, $\mathrm{ZrO}_{2}$-Stabilized $\mathrm{CO}_{2}$ Sorbents." Fuel 127: 94-100.

[10] Tian, X. et al. 2011. "Fabrication and Stabilization of Nanocrystalline Ordered Mesoporous $\mathrm{MgO}-\mathrm{ZrO}_{2}$ Solid Solution." Microporous Mesoporous Mater. 143: 357-61.

[11] Dell'Agli, G., Mascolo, G., Mascolo, M. C., and Pagliuca, C. 2005. "Crystallization-Stabilization Mechanism of Yttria-Doped Zirconia by Hydrothermal Treatment of Mechanical Mixtures of Zirconia Xerogel and Crystalline Yttria.” J. Cryst. Growth 280: 255-65.

[12] Raju, V., Jaenicke, S., and Chuah, G. K. 2009. "Effect of Hydrothermal Treatment and Silica on Thermal Stability and Oxygen Storage Capacity of Ceria-Zirconia." Appl. Catal. B Environ. 91: 92-100.

[13] Sommer, F., Landfried, R., Kern, F., and Gadow, R. 2012. "Mechanical Properties of Zirconia Toughened Alumina with 10-24vol.\% 1Y-TZP Reinforcement." J. Eur. Ceram. Soc. 32: 4177-84.

[14] Dell'Agli, G., and Mascolo, G. 2001. "Agglomeration of 3 mol\% Y-TZP Powders Synthesized by Hydrothermal Treatment." J. Eur. Ceram. Soc. 21: 29-35.

[15] Chu, H.-L. et al. 2014. "Thermal Behavior and Phase Transformation of $\mathrm{ZrO}_{2}-10 \% \mathrm{SiO}_{2}$ Precursor Powder Prepared by a Co-precipitation Route without Adding Stability Agent.” J. Alloys Compd. 616: 413-9.

[16] Li, L., Mao, D., Yu, J., and Guo, X. 2015. "Highly Selective Hydrogenation of $\mathrm{CO}_{2}$ to Methanol over $\mathrm{CuO}-\mathrm{ZnO}-\mathrm{ZrO}_{2}$ Catalysts Prepared by a Surfactant-Assisted Co-precipitation Method.” J. Power Sources 279: 394-404.
[17] Wang, S., Zhai, Y., Li, X., Li, Y., and Wang, K. 2006. "Coprecipitation Synthesis of MgO-Doped $\mathrm{ZrO}_{2}$ Nano Powder.” J. Am. Ceram. Soc. 89: 3577-81.

[18] Duran, C., Sato, K., Hotta, Y., Gocmez, H., and Watari, K. 2015. "Ball Milling Assisted Hydrothermal Synthesis of $\mathrm{ZrO}_{2}$ Nanopowders." Ceram. Int. 41: 5588-93.

[19] Liu, X. L. et al. 2010. "Solvothermal Synthesis and Characterization of $\mathrm{ZrO}_{2}$ Nanostructures Using Zirconium Precursor." Mater. Lett. 64: 1591-4.

[20] Uchiyama, H., Matsumoto, K., and Kozuka, H. 2012. "Solvothermal Synthesis of Micron-Sized Spherical Particles in $\mathrm{TiO}_{2}-\mathrm{ZrO}_{2}$ Binary System." J. Cryst. Growth 338: 201-7.

[21] Sajjadi, S. M., Haghighi, M., and Rahmani, F. 2015. "Sol-Gel Synthesis of $\mathrm{Ni}-\mathrm{Co} / \mathrm{Al}_{2} \mathrm{O}_{3}-\mathrm{MgO}-\mathrm{ZrO}_{2}$ Nanocatalyst Used in Hydrogen Production via Reforming of $\mathrm{CH}_{4} / \mathrm{CO}_{2}$ Greenhouse Gases." J. Nat. Gas Sci. Eng. 22: 9-21.

[22] Mamana, N., Ortiz, A. L., Sánchez-Bajo, F., and Caruso, R. 2014. "A Comparative Study of the Pressureless Sinterability of $3 \mathrm{~mol} \% \mathrm{Y}_{2} \mathrm{O}_{3}$-Stabilized $\mathrm{ZrO}_{2}$ Powders Prepared by the Sol-Gel Method under Different Synthesis Conditions without Modifiers." Ceram. Int. 40: 16829-34.

[23] Kumar, S., Bhunia, S., and Ojha, A. K. 2015. "Effect of Calcination Temperature on Phase Transformation, Structural and Optical Properties of Sol-Gel Derived $\mathrm{ZrO}_{2}$ Nanostructures." Phys. E Low-dimensional Syst. Nanostructures 66: 74-80.

[24] Burtron H. D. 1984. "Effect of $\mathrm{pH}$ on Crystal Phase of $\mathrm{ZrO}_{2}$ Precipitated from Solution and Calcined at $600{ }^{\circ} \mathrm{C}$." Communication of the American Ceramic Society.

[25] Chevalier, J., Gremillard, L., Virkar, A. V., and Clarke, D. R. 2009. "The Tetragonal-Monoclinic Transformation in Zirconia: Lessons Learned and Future Trends." J. Am. Ceram. Soc. 92: 1901-20.

[26] Settu, T. 2000. "Characterization of $\mathrm{MgO}-\mathrm{ZrO}_{2}$ Precursor Powders Prepared by In-situ Peptization of Coprecipitated Oxalate Gel.” Ceram. Int. 26: 517-21. 